\title{
LA VAGINA DENTADA EN UN MITO NIVACLÉ: PÉRDIDAS COMO PARTE DE LA EROTIZACIÓN CORPORAL
}

\author{
Mauricio Arley Fonseca
}

\begin{abstract}
RESUMEN
En el mito nivaclé "Las mujeres del agua", a partir de la corporalidad desnuda y desaculturada, las mujeres motivan el deseo en los hombres por acercarse a ellas. Luego de que los hombres antropomorfos las capturan, ellos descubren que esas mujeres tienen una peculiaridad: comen a través de las vaginas, las cuales están provistas de afilados dientes. Los hombres deben practicar rituales para poder relacionarse genitalmente con ellas; si la aproximación no se da a través del ritual, el desenlace será violento, una castración real y no una apertura erótica heredable. El ritual erótico tiene como práctica central: el baile, luego de ejecutado se caerán los dientes de la vagina. Palabras clave: Vagina dentada, erotismo, nivaclé, baile, mito indígena.
\end{abstract}

\begin{abstract}
In nivacle myth "Water women", from the naked corporality y uncultured, women motivate desire in men in order to approach to them. After anthropomorphous men capture them, they discover that those women have a particularity: they eat through vaginas, which are provided with sharped tooth. Men must practice rituals to be able to intercourse with them; if the practice doesn't happens through the ritual, the final will be violent, a real castration and not an opening and heritable erotic. The erotic ritual has as central practice: dancing, after performance those tooth will fall dawn from the vagina.
\end{abstract}

Key words: Vagina dentata, erotism, nivacle, dance, indian myth.

\section{Inscribir el mito}

Antes de elaborar un acercamiento de lectura al mito nivaclé del Gran Chaco: "Las mujeres del agua", vale citar la ubicación geográfica de los nivaclé, cuya región, el Gran Chaco, es compartida por los países de Paraguay, Argentina y Bolivia, aunque es en Paraguay donde se encuentra la mayoría de esta población indígena, de la familia lingüística mataguayo.

ML. Mauricio Arley Fonseca. Profesor de Literatura y Redacción de la Universidad de Costa Rica y psicólogo clínico. Correo electrónico: marleyfonseca@gmail.com

Recepción: 08- 12- 2012

Aceptación: 19- 01- 2013 
Ante la ubicación geográfica, la reflexión de la grafía se orienta a: ¿cómo empezar?, ¿desde dónde inscribir la lectura mítica? Para esto, Barthes (2000) señala hacia la noción de "pertinencia", cuya etimología latina pertineo remite a verbos castellanos: llegar, conducir, pertenecer, afectar.

Hay un motivo central en el mito por analizar: el previo ritual masculino para acceder al acto sexual con las mujeres. Este motivo orienta el seguimiento hermenéutico del mito nivaclé, cual "Danza del ocho" de las abejas, como exploración previa que ubica el centro alimenticio e inicia la vibración abdominal como marcador del foco vital.

En el mito "Las mujeres del agua", la lectura se dirige hacia las prácticas de sexualidad en un contexto acuoso. Precisamente, el mito refiere una constante vibración abdominal (como abejas), pero esta debe regularse a través de los rituales eróticos para hacer del acto sexual una práctica heredable, y desde luego, obtener la potencial progenie que rememore el acto en futuras realizaciones. Por esto mismo, acudir a estrategias de erotización corporal serán las líneas imaginarias de lectura para acercarse al mito, así se funda el criterio de pertinencia para la lectura mítica.

El presente mito, inscrito dentro de una práctica sexual, con la previa condición de tramitar un ejercicio erótico, conduce a la necesidad de reflexionar acerca de la operación simbólica del mito en la cultura, incluso su inscripción a nivel psíquico en los sujetos culturales. En esto, vale entender el acto erótico como parte de un proceso de reconocimiento del sujeto con el entorno, que al evolucionar, también implica una evolución y contextualización de los ejercicios eróticos.

En la sexualidad, hay un vínculo fundamental con el entorno, así lo plantea Savater: "es la raíz misma de la comprensión del universo" (citado en Puleo 1992: 17). El mito plantea tal comprensión como un problema que trasciende generaciones, dentro de las cuales se reconstruye el conocimiento del grupo en su relación con el entorno evolutivo.

\footnotetext{
Siempre y en todas partes, los mitos, mediante formas y fórmulas muy diversas, tienen relación con los aspectos más importantes de la vida del ser humano [...] El mito llega a hacerse actual en todas las épocas y en todos los espacios.

$[\ldots]$

aquello que debería interesarnos primordialmente no son los "materiales míticos" como tales, sino la forma mítica de conocimiento. (Duch 1998: 27/30)
}

El interés del ser humano por pesquisar el entorno evolutivo, mediante la institución de referentes míticos, caracteriza la condición humana que Duch (1998: 30) nombra como "animal imaginativo", que da sentido a las propias reminiscencias: "quizás ya han sido borradas de su consciente pero que, a pesar de todo, continúan proporcionándole los inagotables materiales de sus sueños". Los mecanismos de acceso a ese gradiente animal son posibles a través de la tradición oral.

Otro caso por considerar en la inscripción de los mitos, consiste en ubicar la actuación femenina como centro del enlace humano, solo a través de su función prolifera de la vida. Campos y Salas (2002: 27) resaltan que la naturaleza o lo divino eran contemplados como una hembra cósmica: Isis, Astarté, Ishtar, Nu Kua, etc. Lo común en estas referencias míticas es la existencia femenina, que adquiere signos como proveedora y protectora, así fue caracterizándose la misma tierra como si tuviese un origen femenino.

En La novela familiar del neurótico, Freud (1996: 1362) comenta que en el sujeto está presente el proverbio latino pater semper incertus est... mater certissima. La certidumbre 
generada por lo materno es principio de vida, pero antes de promover tal condición, se ha de tramitar un ritual de acercamiento a la función vital. Freud reconocía que en este proceso, y más específicamente en el encuentro sexual, en algunos hombres se producían conflictos a nivel psíquico: el temor de perder el pene cuando se introducía en la vagina. Por esto, el análisis del mito "Las mujeres del agua" remite también a una reconstrucción de conocimiento con el entorno, en tanto que, en el mito nivaclé, antes de esas mujeres, los hombres no conocían otras.

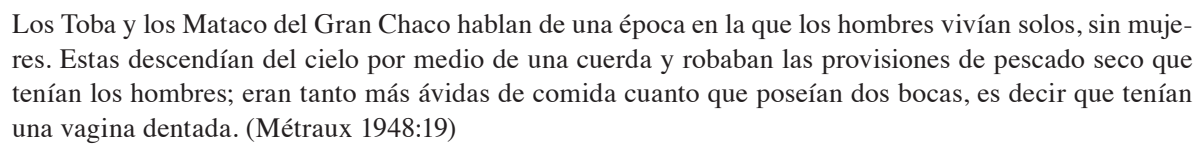

El temor por la vagina pierde su efecto en las regulaciones sociales a partir del proceso ritual. El mito enseña que ante el temor por el cuerpo, es necesario entregar el cuerpo para regular esa cuota de goce que desestabiliza cualquier intento de proximidad.

Lévi-Strauss (1968: 274) ha reconocido una estrecha relación mítica entre las mujeres y los peces: "El quiasma resulta del hecho de que en el plano mítico, la transformación de las mujeres en peces es realizada activamente...". Las mujeres entran en la escena mítica a partir de la presencia de peces, en tanto, donde se reconoce la ausencia de los peces, inicia la recolección de indicios que permitirán descubrir la existencia de mujeres. Con la salida de las mujeres del agua, seducidas por la carne asada, el mito se abrirá para ser leído en su intimidad.

\section{Puntos de lectura del mito}

Mediante la entrega del cuerpo, el sujeto se integra a la realidad circundante. El auto conocerse opera en el desenvolvimiento del sujeto dentro del entorno: las vueltas de la vida que permiten posicionar un yo con respecto a otros actores. El mito nivaclé "Las mujeres del agua" presenta un entorno de apertura a un nuevo conocimiento que cambiará la misma relación corporal entre los actores del entramado mítico:

\footnotetext{
Durante mucho tiempo, aquellos primeros hombres no se dieron cuenta de la existencia de la yinôôt lhavoquei, mujeres del agua. Cuando era la época de la caza de los majôctsí, tucutucu, inesperadamente desaparecía la carne asada de estos animales. (Chase-Sardi; Siffredi; Cordeu 1992: 41)
}

Las mujeres son las figuras que transforman la relación con el entorno, llaman la atención de los hombres, pues precisamente ellas se apropian de los pescados del día, que estaban asados antes de ingresar a las vaginas dentadas. La cita extraída constituye el primer párrafo del mito, por lo que antes de proseguir con las ad-venturas (lo que advendrá) en torno al mito nivaclé, surge una interrogante en la escritura: ¿qué contar de un mito? Vale la consideración literaria de Tolstoi: "Si me preguntasen de qué trata Anna Karenina, tendría que escribir otra vez todo mi libro" (Aguiar 1975: 404). En el caso del mito nivaclé, el argumento atiende a una versión, y como tal, es una de tantas posibles.

En "Las mujeres del agua", el argumento puede exponerse del siguiente modo: un grupo de hombres debe seguir una serie de rituales para poder copular con las mujeres del agua. Los rituales que ejecutan los hombres se dan con la finalidad de causar la pérdida de dientes en las vaginas. Todo el trabajo ritual se leerá como un ejercicio erótico.

Toda búsqueda inicia con preguntas, y así los hombres se interrogan entre sí: “¿Quiénes serán los que se comen nuestros tucutucu asados?" (Chase; Siffredi; Cordeu 1992: 41). Estos hombres, así como las mujeres, son seres antropomórficos: aspecto humano y animal, y solo 
de los masculinos se conoce los nombres individuales, pues las mujeres se nombran con el genérico yinôôt lhavoquei:

Fitsôc' ôyich: jefe; se puede transformar, al menos, en venado.

Shinvuun: lagartija gris, muda, cuidadora de pescados.

Cayin'ô: picaflor, descubre a las mujeres e indica dónde están reunidas.

Jive'clá: tenía un pene gigantesco, lo cargaba sobre sus hombros para correr; muere dos veces y Fitsôc'ôyich lo resucita.

Ofo: paloma, perdió el pene con una de las mujeres de vaginas dentadas.

Cfjanitaa: lagartija verde, entrega un pene extra a Ofo.

Alhu: iguana.

El mito también inscribe órdenes de diferencia en los rasgos físicos de las mujeres de agua, por esto los hombres deben correr y quien llegue primero adonde están las mujeres, escogerá la más bella. La condición excesivamente grande del pene de Jivéclá determina que él llegue de último y deba convivir con una tuerta.

Fitsôc'ôyich pudo aventajar, y se quedó con la mujer que le tocaba a Jive'clá, que era muy linda. En reemplazo le dio a la tuerta. Jive'clá no sabía qué hacer con su enorme falo. Lo cargó dentro de su bolso /.../ se le ocurrió alzarlo sobre sus hombros. (Chase-Sardi; Siffredi; Cordeu 1992: 42)

En el acto sexual, la molestia de Jivéclá fue con respecto al olor que secretaba la vagina de su mujer, por lo que Fitsôc' ôyich: "buscó un cardón y lo puso entre las piernas de su mujer" (Chase; Siffredi; Cordeu 1992: 45). La referencia a la planta "cardón" remite a la botánica, pues el cardón pertenece a la especie cardencha; una de sus características es fungir como diurético, quizá esto era lo que buscaba Fitsôc'ôyich: al estimular la micción, el olor se reduciría casi totalmente. Pero, hay otro asunto, este tipo de plantas se caracteriza por tener hojas, fruto y tallo espinosos, por lo que al contacto con la piel produciría un ligero sangrado, que bien puede servir para explicar el encuentro primero a nivel sexual. Este pasaje por el dolor se constituye como parte del proceso erótico, así lo señalan los compiladores del libro El gateo de los nuestros, de donde se extrae el mito analizado: "la guerra, la caza, el sacrificio y la posesión, componen un paquete solidario con el erotismo" (Chase; Siffredi; Cordeu 1992: 14).

Una figura que resalta en el mito es Fitsôc'ôyich, quien se transforma en venado para ganarse el cariño de unas yinôôt lhavoquei (distintas a las que tomarían como esposas), de tal modo que las mujeres del agua colocaron sus collares en el cuello del pequeño animal y así Fitsôc' ôyich, convertido en venado, corrió hasta que pudo escapar; finalmente llevó los regalos a las futuras mujeres para iniciar el ritual de casamiento; incluso esta expresión del regalo se transmite como enseñanza cultural: "Nuestros ascendientes aconsejaban a las nuevas generaciones que hicieran lo mismo que ellos" (Chase; Siffredi; Cordeu 1992: 46). Lo propio de la práctica erótica es el interés por divulgar su realización como parte de un legado cultural.

Luego de cumplir los rituales, se puede disfrutar del acto sexual sin el temor de una castración real. El proceso erótico del ritual posibilita la inscripción de una castración simbólica, en tanto se regula el goce que ingresa al cuerpo, a través del trabajo cultural por pintar el cuerpo antes desnudo, inscribirlo como sujeto cultural y no cuerpo de las aguas. 


\section{Erótica corporal}

La erótica implica movimiento y este, para efectos del mito, surge ante la falta, que es una falta literal: la falta del pescado asado tututucu. Esta falta genera una incógnita: ¿quiénes se llevaron los pescados asados? Luego de investigar los indicios del entorno, el picaflor Cayin'ô descubrió que las mujeres de agua eran las que tomaban ese objeto preciado. El pescado asado no estaba en su lugar, sino que se introducía en el interior de la vagina dentada.

Cuando los hombres antropomorfos llegan donde las mujeres de agua, observan que ellas están completamente desnudas y su forma de comer es distinta: "las mujeres tiraban entre las piernas la carne de los tucutucu" (Chase; Siffredi; Cordeu 1992: 43). Esa condición orgánica imposibilitaba la penetración sexual, por esto, Fitsôc'ôyich tuvo que transmitir un saber al grupo: debían esperar, bailarían para las mujeres, y así se caerían los dientes. En esto, es reconocible cómo el movimiento corporal, la posibilidad de vestirlo, alimentarlo, etc., serán condiciones propias del erotismo en el acercamiento de los cuerpos, sin que uno de los cuerpos sienta temor de ser violentado por el otro, sino que crezcan en su interrelación simbiótica.

La absoluta desnudez y el coito no son en sí eróticos: "es la intermitencia, como bien lo ha dicho el psicoanálisis, la que es erótica” (Barthes 2000: 19). El cuerpo en apertura es posible en tanto pueda desprenderse de un tejido, que cubre la zona erógena de acceso reproductivo, con la pieza llamada pampanilla, un taparrabo de fibra de caraguatá. De este modo, se integra un elemento natural del entorno con el cuerpo cultural.

El trabajo erótico consiste en hacer del encuentro corporal un lugar para la travesía cultural, y por esto, para Fitsôc'ôyich es imperativa esa voz de la cultura: "Bailaré hasta el amanecer para las mujeres" (Chase; Siffredi; Cordeu 1992: 44). Antes del baile es fundamental la recolección de signos culturales para integrar los cuerpos en el devenir histórico, pues el acto de encuentro no consiste en un solo momento, sino en una trascendencia de memoria histórica: "Estos hombres vigilaron a sus mujeres durante mucho tiempo. Suspendieron la caza de los tucutucu. Y recién cuando estuvieron seguros de mantenerlas a su lado, salieron de nuevo para cazarlos" (Chase; Siffredi; Cordeu 1992: 47).

Ciertamente, luego del baile, como Fitsôc'ôyich lo había advertido, los dientes se desprendieron de las vaginas, pero al iniciar el coito, a los hombres no les gustó el olor que emanaba de las vaginas. A partir de esto se introduce el uso de la planta cardencha para regular la secreción sexual. En esto, vale recordar que parte del proceso de socialización consiste en la regulación corporal, por ejemplo, desde el propio control de esfínteres durante la infancia hasta los niveles de proxemia al interactuar en conversaciones, con sus particularidades en distintas culturas.

Luego de controlar el aroma vaginal, el otro ejercicio ritual será la obtención de objetos para presentarlos como marcas del nuevo vínculo. Por esto Fitsôc'ôyich va a conseguir los collares, que usarán las futuras esposas. Pero además, parte del enlace será con la alimentación; en el mito se menciona el consumo de "piojos" para mascar, los cuales se extraen de un árbol llamado shintinuc, que debe estar asociado a las aves garcitas azuladas, en nivaclé: shintinuc lhafiq'is, vinculadas a concepciones míticas del baile y la lluvia:

\footnotetext{
Por su parte, la garcita azulada (shintinuc lhafiq'is, $\mathrm{n}^{\circ} 16$ ) se concibe como un ser amenazador o sui (bravo); como tal se califica Fanaaj ni is á, otorgándosele la facultad de instigar a «los que traen la lluvia» para que despedacen árboles y personas mediante su arma emblemática, el rayo. Por esa conducta inmanejable e incitadora, se sostiene que son pocas las mujeres versadas en este canto-espíritu. En una fiesta celebrada para el Día Internacional del Indio (1987) en la casa nivaclé, ante un auditorio local y foráneo, cinco ancianas ejecutaron la danza-canto en rueda, dedicada a los Fanjás en los ritos puberales. Se departió luego con una de las bailarinas que al comienzo esquivó su participación en la danza. (Siffredi 2009: 242)
} 
Parte del principio erótico radica en la búsqueda, que ocurre en un entorno cambiante. La tradición nivaclé así lo muestra: "los cantos-espíritus de los Fanjás implementan una forma de control simbólico de factores fundamentales en un entorno frágil”" (Siffredi 2009: 229). La misma actividad cultural cotidiana revive el tiempo mítico: un danzar en medio del ambiente natural, donde las mujeres se encargan de preservar todo un ritual que atiende al mismo sostenimiento del grupo como realidad biológica, en tanto reproductiva, pero también como marca de distinción cultural a partir de las particularidades del propio grupo nivaclé y su tradición erótica ancestral.

\section{Bibliografía}

Aguiar, Vítor Manuel de. 1975. Teoría de la literatura. Madrid: Gredos.

Barthes, R. 2000. El placer del texto y lección inaugural. México: Siglo XXI Editores.

Campos, Á., Salas, J. 2002. El placer de la vida. Sexualidad infantil y adolescente: su pedagogía a cargo de personas adultas. San José: Lara Segura Editores.

Chase-Sardi, M., Siffredi, A., Cordeu, E. (Comp.). 1992. El gateo de los nuestros. Narrativa erótica indígena del Gran Chaco. Buenos Aires: Ediciones del Sol.

Duch, L. 2002. Antropología de la vida cotidiana. Simbolismo y salud. Madrid: Trotta.

Freud, S. 1996. Obras Completas. Madrid: Biblioteca Nueva.

Lévi-Strauss, C. 1968. Mitológicas. Lo crudo y lo cocido. México: Fondo de Cultura Económica.

Métraux, A. 1946. "El dios supremo, los creadores y héroes culturales en la mitología sudamericana". América indígena. 6 (1): 9-25.

Puleo, A. 1992. Dialéctica de la sexualidad. Madrid: Cátedra.

Siffredi, A. 2009. Etno-ornitologia y ecocosmología: las aves tronadoras entre los nivaclé. Revista Española de Antropología Americana. 39 (2): 229-246. 